\title{
Editorial comment: High pressure endoscopic irrigation: impact on renal histology
}

\author{
Fábio C. M. Torricelli ${ }^{1}$ \\ 1 Divisão de Urologia do Hospital das Clínicas da Faculdade de Medicina da Universidade de São \\ Paulo. São Paulo, SP, Brasil
}

\section{COMMENT}

Flexible ureteroscopy for the management of proximal ureteral stones or kidney stones is a first line treatment modality according to European Association of Urology and American Urological Association guidelines $(1,2)$. Due to improvements in the surgical disposable devices, better quality and image resolution of analogical and digital flexible ureteroscopes, and high stone-free rates, RIRS indications are rapidly increasing (3). However, it is a procedure not free of complications and there is robust evidence that high intra-renal pressure used to improve surgical view is related to postoperative complications, such as peri-renal hematomas and infections $(4,5)$. Tokas et al. in a systematic review found that pyelovenous backflow may occur at pressure ranging from 13.6 ro $27.2 \mathrm{cmH} 20$ and complications such as pyelorenal backflow, sepsis, and renal damage are directly related to increased intra-renal pressure (6). In the current paper, Loftus et al. (7) in an experimental study showed that higher intra-renal pressure is related to a deeper tissue penetration of ink, which could represent a greater renal parenchyma damage. Also, in this study, authors have demonstrated the ureteral access sheath (UAS) may prevent a significant increase in the intra-renal pressure, protecting the kidney of an eventual deleterious effects.

In a recent study comparing the intrapelvic pressures during flexible ureteroscopy, mini-percutaneous nephrolithotomy, standard percutaneous nephrolithotomy, and endoscopic combined intrarenal surgery in a kidney model, authors have demonstrated that intrapelvic pressure never exceed $50 \mathrm{cmH} 20$ irrespectively of the technique. During flexible ureteroscopy intrapelvic pressure values ranged from 1.4 to $46.2 \mathrm{cmH} 2 \mathrm{O}$, and irrigation pressure at $40 \mathrm{cmH} 20$, an occupied working channel, and the use of a UAS were factors that reduced intrapelvic pressure (8).

UAS placement as a regular step of flexible ureteroscopy is still a controversial issue. Breda et al in a systematic review and meta-analysis have concluded that UAS has several potential advantages such as to facilitate retrograde intra-renal access, lower intra-renal pressure, protect the ureter, protect the scope, and expedite stone extraction. However, UAS use may also be associated with acute ureteral injury and long-term complications, including ureteral stenosis and hydronephrosis (9). Maybe UAS placement should be individualized according to each case (kidney stone burden and kidney collecting system anatomy) and surgeon experience. Undoubtedly, intra-renal pressure is a major issue that should be kept on mind of all endourologists.

\section{CONFLICT OF INTEREST}

None declared. 


\section{REFERENCES}

1. Assimos D, Krambeck A, Miller NL, Monga M, Murad $\mathrm{MH}$, Nelson CP, et al. Surgical Management of Stones: American Urological Association/Endourological Society Guideline, PART I. J Urol. 2016;196:1153-60.

2. Türk C, Petcík A, Sarica K, Seitz C, Skolarikos A, Straub $\mathrm{M}$, et al. EAU Guidelines on Interventional Treatment for Urolithiasis. Eur Urol. 2016;69:475-82.

3. Heers H, Turney BW. Trends in urological stone disease: a 5-year update of hospital episode statistics. BJU Int. 2016;118:785-9.

4. Yahsi S, Tonyali S, Ceylan C, Yildiz KY, Ozdal L. Intraparenchymal hematoma as a late complication of retrograde intrarenal surgery. Int Braz $\mathrm{J}$ Urol. 2017;43:367-70.

5. Farag M, Timm B, Davis N, Wong LM, Bolton DM, Jack GS. Pressurized-Bag Irrigation Versus Hand-Operated Irrigation Pumps During Ureteroscopic Laser Lithotripsy: Comparison of Infectious Complications. J Endourol. 2020;34:914-8.
6. Tokas T, Herrmann TRW, Skolarikos A, Nagele U; Training and Research in Urological Surgery and Technology (T.R.U.S.T.)-Group. Pressure matters: intrarenal pressures during normal and pathological conditions, and impact of increased values to renal physiology. World J Urol. 2019;37:125-31.

7. Loftus C, Byrne M, Monga M. High pressure endoscopic irrigation: impact on renal histology. Int Braz J Urol. 2021;47:350-6.

8. Doizi S, Uzan A, Keller EX, De Coninck V, Kamkoum $H$, Barghouthy $Y$, et al. Comparison of intrapelvic pressures during flexible ureteroscopy, minipercutaneous nephrolithotomy, standard percutaneous nephrolithotomy, and endoscopic combined intrarenal surgery in a kidney model. World J Urol. 2020:21. Epub ahead of print.

9. Breda A, Territo A, López-Martínez JM. Benefits and risks of ureteral access sheaths for retrograde renal access. Curr Opin Urol. 2016;26:70-5.

ARTICLE INFO

\section{Fabio C. M. Torricelli, MD}

Barata Ribeiro, 380, conj. 74

Sao Paulo, SP, 01308-000, Brazil

Telephone: +55 1127684552

E-mail: fctorricelli@yahoo.com.br
Torricelli FC

https://orcid.org/0000-0002-5845-0894

Int Braz J Urol. 2021; 47: 357-8

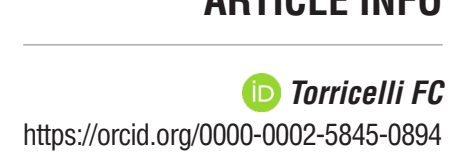

Submitted for publication: October 20, 2020 